\title{
TRADUZINDO OS CHEIROS DO “CHICLETE" DE KIM KI-TAEK
}

\author{
Yun Jung $\operatorname{Im}^{1}$ \\ 1Universidade de São Paulo, São Paulo, SP, Brasil
}

\begin{abstract}
Resumo: Este artigo tem como objeto o livro de poesias Chiclete de Kim Ki-taek, publicado originalmente em 2009 na Coreia e em 2018 no Brasil pela editora 7Letras. O primeiro poeta contemporâneo coreano traduzido para a língua portuguesa é representante de uma poesia coreana urbana, revelando qualidades inumanas da vida megalopolizada e transitando por temas comuns à civilização internacional. Apesar de abordar temas comuns a grandes cidades do mundo contemporâneo, as dificuldades de tradução na passagem entre línguas tão distantes são sempre desafiadoras. Neste artigo, foram selecionadas expressões ligadas a cheiros, pois estas constituem um elemento chave na poética de Kim Ki-taek, e também exemplificam várias questões complexas que envolvem a tradução de aspectos culturais e semânticos entre as duas línguas. Ao analisar cada vocábulo e a sua respectiva tradução, e comparando com a tradução para o espanhol, procurou-se mostrar a necessidade de recorrer a variados procedimentos em busca de um equivalente poético adequado.
\end{abstract}

Palavras-chave: Poesia Coreana; Tradução Poética; Tradução Cultural

\section{TRANSLATING SMELLS IN KIM KI-TAEK'S “GUM”}

\begin{abstract}
The object of this article is Gum, book of poems by Kim Kitaek, originally released in Korea in 2009 and published in Brazil by 7Letras publishing house in 2018. The first Korean contemporary poet introduced to Brazilian readers is a representative of an up-to-date Korean urban poetry, revealing a non-humane quality of a megalopolitan life and transiting through common themes to the international civilization. Despite its approach to common themes to big cities of the contemporary world, the difficulties in translating such immensely different languages are always
\end{abstract}


challenging. In this article, it was selected expressions referring to smells, for these constitute a very important element in Kim Ki-taek's poetry and also bring about complex issues involving translation of cultural and semantic aspects between the two languages. By analyzing each selected word and its translation, and comparing it with the translation into Spanish as well, it turned out to be clear the search for diverse translation procedures to reach for an adequate poetic equivalent.

Keywords: Korean Poetry; Poetic Translation; Cultural Translation

김기택 시집 “껌”에 나타난 냄새들의 번역 문제

초록

본 연구는 2009년 발표된 김기택의 시집 “껌”을 대상으로 하고 있다. 동 시집은 7Letras 출판사를 통해 2018년 브라질에 번역.출판되어 김기택은 브라질에 소개된 최초의 한국의 동시대 시인이 되었다. 김 기택의 시는 다분히 도시적이며, 대도시 문명에서 흔히 관찰되는 반 인간적인 면모들을 파헤치면서 현시대의 국제화된 문명을 이루는 주제들을 다루고 있다. 현시대의 세계 대도시들에 공통되는 소재들 임에도 불구하고 포르투갈어와 한국어와 같이 판이하게 다른 두 언 어간의 번역행위는 항상 난제로 남는다. 여기서는 냄새와 관련된 단 어들을 선택하여 그 번역에 대해 논의를 하고자 하였는데 그 이유는 우선 김기택의 시에서 냄새가 매우 결정적인 역할을 하고 있을 뿐 아니라, 한-포 시번역에 있어 여러 복합적인 문화적.의미론적 문제 들의 본보기가 되고 있기 때문이다. 냄새와 관련된 각 단어들을 분 석하고, 또 스페인어 번역과 비교하며 그 번역가능성을 타진하는 작 업을 통해, 적절한 시적 표현을 추구하는 데 있어 매우 다양한 방법 론이 동원되어야 하는 것과, 정확이 단어가 없는 경우 그 주변을 조 작하는 기교에 대해 토론하였다.

키워드: 한국시, 시번역, 문화번역 


\section{A poesia coreana moderna}

Quando se fala da poesia coreana moderna, considera-se o ano de 1908 como ponto de partida, com a publicação do poema "Do mar ao menino" de Choe Nam-seon (1890-1957) ${ }^{1}$ na revista Sonyeon (Menino). Até então, o fazer poético dos nobres letrados estava lastreado na tradição ideogrâmica chinesa, apesar da promulgação do hangul - escrita coreana de cunho alfabético - pelo Grande Rei Sejong (1397-1450) em 1446². Inventado pelo próprio rei com o objetivo de facilitar a comunicação e a educação moral confuciana do povo analfabeto, a escrita foi desprezada pelos nobres letrados em ideogramas chineses, por considerá-la "vazia" de sentido, e, portanto, de filosofia. Somente na virada do século XX, hangul ganha importância mais generalizada, com a modernização/ ocidentalização do país e edição de jornais, aliada à ameaça da identidade coreana perante as investidas de potências estrangeiras no contexto do neocolonialismo.

Assim, foi no próprio ano da publicação do poema de Choe Nam-seon (1908) que se deu a formação da primeira Sociedade de Pesquisas em Lingua Coreana, a partir da qual foram feitas pesquisas e publicações sistematizadas sobre a gramática da língua coreana escrita em hangul. A referida revista, que buscava levar informações novas - em grande parte ocidentais e/ou ocidentalizantes, como geografia, ciência, literatura estrangeira traduzida etc. - à população jovem, teve um papel fundamental na ampla consolidação de uma forma de escrever em hangul como instrumento de comunicação de todos os coreanos. O poema traz a imagem de on-

\footnotetext{
${ }^{1}$ Poema-prólogo que abre o primeiro número da revista, editada pelo próprio poeta, em $1^{\circ}$ de novembro de 1908 . A revista teve 23 edições até maio de 1911 , quando foi obrigada a fechar pelo governo-geral japonês durante a ocupação japonesa (1910-1945).

${ }^{2}$ A escrita hangul é composta hoje de 14 consoantes e 10 vogais básicas (19 consoantes e 21 vogais combinadas na lista estendida), e é classificada como "código traçal" (Feature Code) em vez de alfabeto na árvore linguística, devido ao caráter icônico de suas consoantes, pois estas caricaturam a conformação dos órgãos fonadores ao pronunciar cada som.
}

Cad. Trad., Florianópolis, v. 39, nº esp., p. 297-317, set-dez, 2019 
das gigantes do mar sobrevindo aos coreanos como uma grandiosa e inescapável onda de mudanças, e a mensagem de que os jovens protagonistas dos tempos devem recebê-la de braços abertos.

É comum dividir a poesia coreana moderna do século XX em duas grandes vertentes: a lírica e a realista/participativa - social e ideológico-política. Tal modelo binário é obviamente reducionista e enganador, especialmente quando se leva em consideração o contexto histórico coreano do século passado, condensado de acontecimentos quase inverossímeis e que impossibilitariam qualquer poeta de produzir uma poesia completamente isenta do chamado realismo participativo. Acontecimentos que sucederam a rápida derrocada da dinastia Joseon (1392-1897) no último quarto do século XIX incluem: o embate de potências estrangeiras sobre a península coreana na virada do século com vistas a tomá-la como colônia; a ocupação japonesa (1910-1945) e a exploração colonial no contexto das duas grandes guerras em que Japão foi protagonista; a libertação repentina e despreparada dada à Coreia em consequência da rendição japonesa em 1945; a bipartição ideológica do povo e a divisão da península sob tutela dividida entre a União Soviética e os Estados Unidos em Guerra Fria; a Guerra da Coreia (1950-1953) fratricida que deixou um saldo de 2 a 3 milhões de mortos, civis na maioria; a revolução estudantil de 19 de abril de 1960 e a abdicação do então presidente; o golpe militar de 16 de maio de 1961 e a dura ditadura militar que se seguiu pelas décadas 60 e 70; o massacre de Gwangju em 1980 e um novo golpe militar em 1981 seguida da ditadura da $5^{\text {a }}$ República; e a revolução civil de 1987 pela democracia plena. Se todos esses acontecimentos tinham como pano de fundo o já bem conhecido Milagre do Rio Han, que fez da Coreia o maior representante do grupo dos Tigres Asiáticos da década de 1980, o final do século foi coroado por uma grave crise financeira em 1997, que teve como uma das consequências a abertura da economia e os fenômenos inerentes ao neoliberalismo mundial.

Durante a ocupação japonesa, o próprio ato de escrever poesia - de conteúdo supostamente lírico, regionalista, surrealista ou qualquer outro - era resistência, um ato participativo, portanto, 
sob o tolhimento do uso da língua coreana pelo governo-geral japonês. E, após a independência e a Guerra da Coreia, poeta nenhum poderia ter estado alheio às transformações galopantes da sociedade coreana, com suas glórias e sombras. Como explica o crítico Kwon O-ryong ao programa Entrelinhas da TV Cultura, "a percepção profunda da desarmonia e discórdia inescapáveis da realidade constitui um dos elementos mais importantes da consciência poética moderna coreana". ${ }^{3}$

E, apesar dos protestos e provas em contrário, a divisão dos poetas coreanos em duas categorias - lírica e participativa - entre estudiosos e críticos permeou o século XX como que reproduzindo a divisão ideológica, territorial e política vivida pelo povo coreano desde então. A poeta Shin Dal-ja contesta, na entrevista concedida na mesma ocasião:

Dentro dessa distinção que se faz da poesia coreana, sou poeta lírica de tradição. É comum se referir à poesia lírica como covarde, individualista, alienada e fechada na sua experiência pessoal, mas qualquer poeta é fruto do seu tempo e está inserido no seu contexto maior.

E a recíproca também era verdadeira, como no caso de Han Daesu, considerado o pai da música folk-rock coreana, perseguido pela ditadura militar por canções que não tinham como intenção desafiar o regime. Teve que se exilar em 1975 com sua canção inofensiva $M e$ dê Água, considerada subversiva, pois faria alusão à tortura da água praticada pela ditadura de Park Jung-hee (1961-1979). ${ }^{4}$

\footnotetext{
${ }^{3}$ Por ocasião de sua visita ao Brasil, integrando a delegação enviada por Literature Translation Institute of Korea (LTI Korea) para comemorar os 50 anos de relações diplomáticas Brasil-Coreia em 2009. A entrevista foi televisionada em 01/08/2010. Disponível em < https://www.youtube.com/watch?v=zyxMSrNi0RY $>$.

4 Tortura que consistia em obrigar o torturado a engolir água indefinidamente. Retornado à Coreia em 1989 e ativo até hoje, o cantor-compositor afirma que nunca tivera a ideia de fazer tal alusão na época.
} 


\section{A poesia coreana hoje e Kim Ki-taek}

A Coreia emerge do século XX completamente transformada, e certamente já não é mais possível caracterizar a sua poesia hoje pelo estereótipo mencionado. Com a abertura da sua economia em grande escala para o capital estrangeiro em consequência da crise financeira, sua população urbana hoje ultrapassa os $80 \%$, e $60 \%$ da população viaja para fora do país anualmente (dados de 2018). Os coreanos se tornaram cidadãos do mundo e transitam com desenvoltura no cosmopolitismo internacionalizado da megalópole Seul, com seus 10 milhões de habitantes, $20 \%$ da população do país. Seus produtos culturais ganharam o mundo já há algum tempo no cinema, música popular, novelas e culinária, com um toque globalizante, "americanizado" para os críticos. Entretanto, a mesma globalização tem sido mais lenta na literatura, apesar dos esforços do Literature Translation Institute of Korea ${ }^{5}$ e foi somente em 2016 que uma obra coreana ganhou destaque com a premiação de $A$ Vegetariana de Han Kang $^{6}$ com o Man Booker International, na Inglaterra.

É curioso comparar os escritores coreanos que visitaram o país em 2009, por ocasião da comemoração dos 50 anos de relações diplomáticas Brasil-Coreia e aqueles enviados neste ano de 2019, em homenagem aos 60 anos. ${ }^{7}$ Em 2009, integravam a comitiva Lee Ho-cheol, representante máximo da chamada Literatura da Divisão [peninsular], portanto, participativa, e a poeta "lírica" Shin Dal-ja, ambos citados acima. Já neste ano de 2019, o poeta Kim Ki-taek e

${ }^{5}$ Entidade ligada ao Ministério da Cultura, Esportes e Turismo da Coreia do Sul, que tem como missão divulgar a literatura coreana no mundo, apoiando financeiramente tradutores e editores de obras coreanas, com uma gama variada de ações que incluem workshops de tradução, prêmios, programa de residência para tradutores, envio de autores coreanos ao exterior etc.

${ }^{6}$ Publicada pela primeira vez no Brasil em 2013 pela editora Devir, tradução minha, a edição encontra-se esgotada. A editora Todavia, que adquiriu os direitos autorais da obra pós-premiação do Man Booker International, publicou uma outra edição em 2018, traduzida por Jae Hyung Woo.

${ }^{7}$ Ambas as visitas organizadas pelo Ministério da Cultura, Esportes e Turismo da Coreia do Sul por meio da Literature Translation Institute of Korea (LTI Korea).

Cad. Trad., Florianópolis, v. 39, nº esp., p. 297-317, set-dez, 2019 
os romancistas Kang Byoung Yoong e Park Min-gyu que integraram a comitiva atestam que a literatura coreana já não mais cabe na divisão binária que dominou o século passado.

Kim Ki-Taek é representante de uma poesia coreana contemporânea marcada por urbanidade cosmopolita internacionalizada, como afirma Nelson Ascher no prefácio do livro de poesias Chiclete, publicado em 2018 no Brasil.

\begin{abstract}
[...] ainda há três gerações, o que os ocidentais buscavam no oriente era a diferença, o exótico, e isso se aplicava à prosa e à poesia. Acontece que, para bem ou para mal, essa diferença não existe mais, ou melhor, há provavelmente mais diferenças no interior de uma megalópole cosmopolita do que entre dois pontos do planeta, por mais afastado que estejam um do outro. [...] o grosso se deve à dinâmica própria da civilização industrial e/ou pós-industrial [...]. Seus poemas estão ligados a esta civilização internacional contemporânea, profundamente ligados [...] (9)
\end{abstract}

Sua poesia é essencialmente "antilírica e antissentimental" (Kim 12), e com uma estética calcada no "vazio intimista", melhor explicada pelo próprio poeta, por ocasião de sua visita a São Paulo:

Sinto frequentemente que a energia poética, de me regozijar no momento em que me comunico com as coisas e me torno um com os objetos, secou. [...] o que o meu poema faz é observar friamente o meu próprio ser, impossibilitado de escrever poesias líricas [...] (Kim, s.p)

\title{
3. A escolha de Chiclete
}

A escolha do autor coreano a ser traduzido carrega um peso quase que insuportável quando se conhece o que há de poesia coreana traduzida para o português até hoje: 


\section{Tabela 1:}

\begin{tabular}{|l|l|l|l|}
\hline $\begin{array}{l}\text { Olho-de-corvo e outras } \\
\text { obras de Yi Sang } \\
\text { (Yi Sang) }\end{array}$ & Yun Jung Im & Perspectiva & 1999 \\
\hline $\begin{array}{l}\text { Sijô: Poesiacanto coreana } \\
\text { clássica } \\
\text { (vários) }\end{array}$ & $\begin{array}{l}\text { Yun Jung Im e } \\
\text { Alberto Marsicano }\end{array}$ & Iluminuras & 1994 \\
\hline $\begin{array}{l}\text { O pássaro que comeu } \\
\text { o sol: } \text { poesia moderna } \\
\text { coreana (vários) }\end{array}$ & Yun Jung Im & Arte Pau-Brasil & 1993 \\
\hline
\end{tabular}

Fonte: Dados do autor

Além dos volumes acima, devo citar Contos da Tartaruga Dourada (Kim Si-seup), obra do século XV considerada a primeira narrativa ficcional coreana, pois, apesar de ser uma coletânea de 5 contos, traz vários poemas inseridos em 4 deles. Além disso, a poesia moderna coreana traduzida até agora - $O$ pássaro que comeu o sol: poesia moderna coreana (vários) e Olho-de-corvo e outras obras de Yi Sang (Yi Sang) - fora produzida em sua maioria na primeira metade do século $\mathrm{XX}$. Em outras palavras, trata-se de um passado remoto no caso coreano, à luz dos acontecimentos históricos dos últimos 100 anos.

A escolha tradutória envolve questões de gosto e de leitura crítica, mas também de outros fatores que estão fora do alcance do tradutor. Como aponta Brother Anthony of Taizé (o mais importante e profícuo tradutor de poesia coreana para a língua inglesa, que já publicou 35 volumes de literatura coreana, sendo 29 de poesia), em sua apresentação para o $3^{\circ}$ Forum de Escritores Coreanos:

This brings us to the question of what poems we will translate, the reasons for a choice that every translator has to make. For Koreans in general, the obvious top candidates for translation have long been the poems which they have learned at school, considered to be the 'masterpieces of 
Korean poetry'. The selection of certain poems for use in school textbooks was often made on the basis of their nationalistic value as expressions of anti-Japanese resistance; otherwise, they were seen as embodying beauties and humane values that schoolchildren should learn to respect and follow [...] generations of Koreans accepted unquestioningly their teachers' assurances that these poems were outstanding works of poetry, worthy to stand beside anything written in the outside world. These, it was long thought, were the poems which would establish the high quality of Korean poetry if only they were 'well' translated. (Taizé)

Nesta mesma fala, Brother Anthony of Taizé, vivendo na Coreia desde 1980, aponta uma outra dificuldade, de ordem diversa:

[...] it is the way in which my native England, Europe or the West are now in some ways foreign to me. I have not kept up in my daily life with social, cultural changes; I do not speak the language of contemporary critical literary discourse; I do not have any widespread network of literary friends [...] As a result I am not sure of recognizing the Korean poets who might interest the outside world, and I do not have access to major publishers in order to promote them and get them published, have them invited to literary festivals etc. I am not part of cultural life 'over there' [...]. Again, it is not because Korean readers and critics admire a poet that he or she will find a wide readership once translated and published. Much depends on finding advocates in the target countries, professional readers of world literature who find something of interest in this or that younger, innovative Korean writer and talk enthusiastically that writer to publishers and critics. (Taizé)

As duas passagens acima nos remetem à visada sincrônica da tradução poética do Haroldo de Campos, inspirada na ideia da poé- 
tica sincrônica de Roman Jakobson, ${ }^{8}$ isto é, que qualquer escolha de tradução literária deve priorizar elementos capazes de entrar na corrente sanguínea do tempo e espaço de chegada. É verdade que a minha escolha partiu de um gosto pessoal, mas, na condição de alguém que vive no Brasil, em contato diário com o meio ambiente para o qual a tradução será transplantada, levei em consideração justamente a qualidade urbana da poesia de Kim Ki-taek, como elemento capaz de permanecer entre os leitores de poesia brasileiros. Em outras palavras, mais do que procurar trazer ao público brasileiro um autêntico representante da poesia coreana atual, mesmo porque esse o chamado cânone de poesia coreana do século XXI ainda está por se consolidar, busquei sintonizar a minha preferência com o chamado "discurso crítico literário atual" de especificidade brasileira, apontado por Brother Anthony.

\title{
4. Os cheiros do Chiclete
}

O próprio poeta, e também seus críticos, já explicitaram em numerosas ocasiões sobre o modus operandi do seu fazer poético, em que, a partir de detalhamento de seus objetos poéticos, busca fazer com que o leitor efetivamente sinta todas as sensações encarnado nos mesmos:

\begin{abstract}
[...] levantar e selecionar meticulosamente os detalhes que serão arrolados, planejar sua ordem e seu modo de exposição, e, quando isso fica pronto, é o conjunto que se põe em movimento, gerando sentidos, sensações e sentimentos (Kim 7-8).
\end{abstract}

\footnotetext{
${ }^{8}$ Roman Jakobson fornece os subsídios para a elaboração desse conceito, quando escreve: “A descrição sincrônica considera não apenas a produção literária de um período dado, mas também aquela parte da tradição literária que, para o período em questão, permaneceu vivia ou foi revivida. [...]”. (Campos 207)
} 
De fato, a questão sensorial é decisiva na poética do Chiclete, e mais especificamente, sensações nada agradáveis, como uma criança chorando no andar de cima, pneus esmagando um gatinho, e "dentes que ficam eretos assim que penetram na coxa branquinha do galeto" (Kim 48). Mas, dentre as sensações, talvez a mais eloquente tenha sido o paladar: "ele estimula a pensar sobre o que comemos, sobre o comestível, ou melhor, sobre como e por que se torna comestível (ou não) o que comemos" (Kim 12).

Estranhamente, porém, o after-taste mais eloquente da experiência de traduzir Chiclete havia sido para mim os cheiros, talvez por ser a mais primitiva das sensações, e talvez também pela extrema dificuldade encontrada em traduzir tais cheiros, que me fizeram suar frio, deixando uma profunda angústia de não ter conseguido transmitir a sensação vívida deixada pelos cheiros em Chiclete. Mesmo quando não há nenhuma palavra direta referente a cheiro, os poemas exalam odores, como no caso de Mia: Zona de revitalização:

Casas são carregadas em caminhões basculantes.

Balançam feito carne congelada feito linguiça feito pé de porco defumado

Junto com a carreta que capenga.

[...]

Telhas, tijolos, muretas, vigas de ferro e privadas, ladrilhos e isopores,

Espelhos partidos e caixas de ovo, crucifixos e camisinhas se emaranham num monte só

Facilitando o trabalho da escavadeira.

[...]

Casas são carregadas em caminhões basculantes

Misturadas às embalagens de lámen, latas, caixa de leite, absorventes. (Kim 60)

Sabendo intuitivamente da importância dos cheiros nas nossas memórias e emoções, processos de identificação e associação, e por mais que Seul seja igual a todas as megalópoles do mundo, 
com cheiros mais ou menos iguais a qualquer outra metrópole, as palavras utilizadas para nomear os cheiros trazem um fator cultural próprio, compondo uma imagem sensorial dificilmente transmissível a um olhar estrangeiro. Como aponta Gregory Rabassa, o mais importante tradutor americano de obras em português e espanhol para a língua inglesa.

It seems easy to match like words ( $\operatorname{dog} / c a \tilde{o})$ and proceed on. What $d o g$ connotes for me, however, is probably different from what cão suggests for António Lobo Antunes, although in common usage he must of course be satisfied with cão as I must be with dog. (Rabassa 13)

Se essas observações são válidas para uma palavra como cão, o que dirá de cheiros? Porquanto sejam pertinentes, a observação acima é paralisante, mas, mesmo que se tome como uma retórica a contaminação cultural que há em cada vocábulo, o pouco alcance que tem o olfato, talvez o ímpeto de escrever sobre a tradução impossível - dos cheiros do Chiclete esteja ainda ruminando na angústia de não ter conseguido transmiti-los adequadamente, e a necessidade de anexar uma justificativa.

\section{A tradução dos cheiros do Chiclete}

\section{Poema Panceta de porco}

[...]

Aquele cheirinho de grelhado de quando devorava a carne esfaimado (ver (a))

Já se fora

E ficara apenas o fedor do terror do animal diante do abate $(\operatorname{ver}(b))$ 
Tampando como bolas de algodão as minhas narinas saciadas.

[...]

O cheiro nauseante de onde ainda restam gritos e esperneios (Kim 14, grifos meus)

\section{a) "Gosohan hyang" (cheirinho de grelhado)}

No dicionário online do portal coreano NAVER (www.naver. com), o mais utilizado por internautas coreanos (75\%), a expressão é traduzida em inglês como "spicy fragrance". Uma rápida pesquisa em outros dicionários online mostrou resultados como "smell of sesame oil", "aromatic", "sweet smell", "savory smell", "nutty smell", entre alguns outros sem nenhum resultado. Essa pequena lista é suficiente para perceber a falta de consenso entre os dicionários para um cheiro que é prontamente identificável entre os coreanos. Ainda mais grave: note-se que o dicionário mais utilizado traz uma tradução para o inglês que, além de totalmente discrepante das demais, é, com certeza, a tradução mais equivocada de todas, pois o cheiro remete justamente a algo que é o contrário de "spicy". Para entender o cheiro de "gosohan-hyang" é preciso ter em mente que a cozinha coreana é famosa por ser bem condimentada, em que a pimenta e o alho têm papel decisivo. Por isso, um cheiro ou gosto que seja gostoso e que não seja condimentado é justamente o "gosohan-hyang", e, dentro do repertório de condimentos usados na cozinha coreana, o gergelim e o óleo de gergelim podem ser considerados representantes dessa categoria de cheiro (ou gosto). Por isso, o mesmo site NAVER, na seção de dicionário coreanocoreano, traz como principal descrição: "cheiro/gosto semelhante àquele de gergelim torrado ou de óleo de gergelim". Em outras palavras, o gosto não é exclusivo de gergelim, sendo esse apenas o melhor exemplo, e, por isso, um dos dicionários online traz a expressão "nutty smell", pois o cheiro também pode ser atribuído a amendoim ou nozes.

No poema em questão, "gosohan hyang" foi utilizado para descrever o cheiro de panceta de porco fatiada sendo grelhada, um 
prato muito apreciado pelos coreanos e que é assada numa grelha na própria mesa pelos comensais. A tradução desse verso em espanhol traz a expressão "sabroso aroma", aproveitando a tradução "savory smell" do Google Translate. Para tradução em português "cheirinho de grelhado" foi acrescentada a palavra "grelhado", além do sufixo "-inho", para dar a ideia de um cheiro bom, aproveitando o recurso do diminutivo em português.

\section{b) "Norin-nae" (fedor)}

No referido dicionário online NAVER coreano-coreano, o vocábulo é descrito como "cheiro exalado por gordura de carne animal, ou cheiro de proteína animal - como carne ou pele - queimando", enquanto na seção coreano-inglês está traduzido como "a fur-scorching smell, a foul smell, the smell of burning fat [hair], the smell of a skunk" (cheiro de pele queimando; cheiro desagradável; cheiro de gordura [cabelo] queimando, cheiro de gambá). Pelo exposto, é possível imprimir uma falsa ideia de que o cheiro "norin-nae" está mais associado à queima, mas isso não é verdade. Por exemplo, no poema No vagão do trem de segunda, há um verso contendo o mesmo cheiro, sinestésico, aliando "norin-nae" à secura:

\section{Agora, [o vagão] mal retinha um odorzinho árido todo ressecado}

Envelhecendo impregnado na fundeza das espumas. (Kim 57, grifos meus)

"Norin-nae" é certamente um cheiro desagradável, mas não chega a ser um fedor, e o recurso do português do diminutivo foi mais uma vez aproveitado, desta vez para dar a conotação pejorativa que a expressão carrega.

Com isso em mente, e voltando para o poema "Panceta de porco", a opção pelo "fedor", uma expressão muito generalizante, se 
deveu ao ritmo/rima conseguido por "fedor do terror animal", jogo obviamente inexistente no original. ${ }^{9}$

O mesmo cheiro aparece também no poema "Sorrindo" dentro de uma foto antiga. Aqui, o cheiro aparece na forma de uma variante, "nurin" em vez de "norin", a troca do "o" pelo "u" emprestando à expressão uma sensação mais suja e repulsiva.

Vejo a mim, [...], escondendo com o terno a ceroula exalando cheiro amarelado [...] (Kim 74, grifos meus)

Aqui, preferi resgatar a etimologia da palavra, derivada de "amarelo", isso porque as referências acima - gordura, carne (não crua), pele de animal - possuem tons de amarelo, motivo pelo qual a palavra é derivada da cor amarela, mas com uma sensação apenas desagradável ("norin") ou repulsivo ("nurin"), que poderia ser expressa em português com palavras como amarelado, amarelão etc.

\section{c) "Birin-nae" (cheiro nauseante)}

No dicionário NAVER coreano-coreano o vocábulo é descrito como "cheiro ou gosto em coisas como soja crua, peixe, sangue de animal etc." e, no coreano-inglês, como "fishy smell", e em outros sites, como "smell fishy", "stink of fish", "have a fishy smell". Obviamente o cheiro não é só de peixe - note-se que no dicionário coreano, o mesmo cheiro serve para soja crua e sangue de animal, e, acrescento, até sangue humano em certos casos - , apesar dos dicionários coreano-inglês online que fazem referência a peixe, sem exceção. No livro, esse cheiro "peixento" serviu para se referir à panceta de porco, sopa de galinha, vento de areia entre vários outros, e somente uma ocorrência se referia, de fato, à peixe, conforme é mostrado abaixo:

${ }^{9}$ A tradução para o espanhol traz "hediondo olor". 
- Cheiro de panceta de porco grelhado:

O cheiro nauseante de onde ainda restam gritos e esperneios (Kim 14, grifos meus)

Tradução em espanhol: El hedor que todavía tiene gritos y aullidos (Kim 14, grifos meus)

- Cheiros diversos de carne:

Chiclete que brincava com o sangue, a carne e o cheiro nauseante (Kim 23, grifos meus)

Tradução em espanhol: El chicle ha jugado con esa sangre, esa carne y ese hedor (Kim 23, grifos meus)

- Cheiro de peixe assado:

Cheiro nauseante hoje na mesa do jantar. (Kim 31, grifos meus)

Tradução em espanhol: Hoy la cena huele a carne/El olor/ Reposa redondo sobre el plato blanco (Kim 30, grifos meus)

- Cheiro abstrato:

Creio não poder mais desistir dessa desconfortável velocidade

Que range os dentes e exala fedor (Kim 35, grifos meus)

Tradução em espanhol: no puedo quedarme quieto y bramo emitiendo um olor venenoso (Kim 36, grifos meus)

- Cheiro de galinha depenada:

Depois de ter sido lavada na água fervente do odor repugnante e até da textura dura e seca (Kim 51, grifos meus) Tradução em espanhol: olores (Kim 55, grifos meus)

- Cheiro do vagão do trem de segunda:

O cheiro ascoso passado de geração a geração,

O cheiro ascoso atravessado pela virilha, sovaco, narinas

Que não perde a identidade [...] (Kim 57, grifos meus)

Tradução em espanhol: El olor a pescado (Kim 62, grifos meus)

- Cheiro de vento de areia:

Cheiro ascoso de pó de terra. (Kim 61, grifos meus) 
Tradução em espanhol: olor nauseabundo (Kim 68, grifos meus)

- Hálito:

E da minha boca um cheiro nauseante se expelia em golfadas massudas. Kim 71, grifos meus)

Tradução em espanhol: olor a pescado (Kim 78, grifos meus)

As expressões "cheiro nauseante", "odor repugnante" e "cheiro ascoso" são praticamente sinônimas, mas todas elas trazem a consequência do cheiro, e não o cheiro em si, o que vai de contra a intenção do poeta de fazer com que o leitor sinta, ele mesmo, todas as sensações, sem nomeá-las.

\subsection{Poema No vagão do trem de segunda}

[...]

Dentre os inúmeros cheiros de cosméticos

$O$ vagão do trem de segunda escolhera justamente o mais

fétido e conservava tenazmente a sua essência. (ver (a))

[...]

Mesmo o cheirinho doce dos enamorados que outrora teria atiçado torridamente as suas zonas eróticas (ver (b))

\section{a) "Jirin-nae" (o [cheiro] mais fétido)}

Enquanto o dicionário NAVER coreano-inglês traz a tradução de "stench of urine" (mau-cheiro de urina), o dicionário coreanocoreano descreve como "cheiro igual/parecido com aquele exalado pela urina". Considerando-se que "igual" em coreano também significa "semelhante" (pois, de outro modo, o correto seria "cheiro exalado pela urina"), o cheiro não é exclusivo de urina, que é, justamente o caso, neste poema. 
Note-se que o cheiro no poema é de cosméticos, e não de urina. É verdade que, como usuária de cosméticos há décadas, devo dizer que muitos cosméticos baratos têm cheiro semelhante ao de urina ressecada das ruas. Ainda assim, devo discordar da sua tradução para "el olor a orín" em espanhol, pois a correspondência pode não ser óbvia para os leitores em geral, mas o motivo mais importante reside no fato de que nem "stench of urine", e nem "cheiro igual/parecido com aquele exalado pela urina" trazem uma informação que acredito ser essencial neste caso. Pois embora "jirin-nae" seja, genericamente, cheio de urina, ele remete muito mais ao mau-cheiro quando a urina resseca numa superfície externa após entrar em contato com o ar. Ou seja, é intrínseco a este cheiro o tempo transcorrido e a aderência da substância maucheirosa numa superfície e a sua absorção nela, e que expressa a sensação do velho vagão do trem de segunda. Busquei compensar esta superposição de significados com a introdução - inexistente no original - do superlativo "o mais".

\section{b) "Dan-nae" (cheirinho doce)}

Certamente "dan-nae" significa "cheiro doce", pois "dan" é doce em coreano. O mesmo cheiro aparece também no poema "Cochilando" enquanto lia, e nos dois casos foi traduzido por " $\mathrm{dul}$ ce olor" em espanhol.

Como se estivesse à espera, o sono avançou de uma vez com o seu cheirinho doce. (Kim 43, grifos meus)

Entretanto, a minha opção pelo uso do diminutivo "cheirinho doce" dos enamorados e do sono foi para exprimir a sensação de lascívia, no primeiro caso, e de languidez no segundo. 


\section{Considerações finais}

Conforme exposto, os procedimentos utilizados para traduzir os cheiros inominados em português e espanhol incluíram acréscimos, explicativos ou não, metonímias e metáforas, opção por rimas/ritmos, reprodução etimológica estranhadora, adição de diminutivos e superlativos de caráter emotivo etc., num aparente "vale-tudo" na tentativa de reproduzir uma sensação aproximada na língua de chegada. No geral, acréscimos qualificativos foram mais utilizados como recurso para suprir a falta de vocábulos equivalentes. Por exemplo, no caso de "nauseante", "ascoso" e "repugnante", que são sinônimos, mencionaram a consequência do cheiro em vez do cheiro em si, além do que a opção por um ou outro foi aleatória, é preciso confessar, e em grande medida apenas para fugir de repetições. Em outros casos, como as traduções para o espanhol "a carne”, "a pescado" e "a urina", especificaram demais o cheiro, limitando o seu escopo, enquanto que nos casos como "fedor" (hedor em espanhol, usado em várias situações) ou "sabroso" generalizam em demasia.

Alguns acréscimos foram mais longe emprestando toques metafóricos, sinestésicos ou etimológicos como "venenoso", "hediondo", "amarelado", "árido" etc. Ao analisar o resultado, pode-se dizer que são justamente essas soluções que saltam aos olhos, como por exemplo no caso do cheiro abstrato da velocidade no poema "Morrer ou matar ou ganhar rodas na bunda", em que "olor venenoso" acrescenta um atributo criativo em sinergia com o tema da morte, e "hediondo olor" no poema "Panceta de porco", com um atributo que se soma ao clima do terror do abate. Na tradução para o português, "cheirinho de grelhado" - que traz um acréscimo explicativo e o diminutivo compondo a imagem sensorial do cheiro prazeroso - , além do "cheiro amarelado" - estranhamento etimológico - e "odorzinho árido todo ressecado" — sinestesia - podem ser destacados como soluções mais criativas. Em outras palavras, os resultados apontam os acréscimos ousados como os pontos altos da tradução poética criativa, fazendo-nos lembrar da lição deixada por Haroldo de Campos: 
O problema da tradução criativa só se resolve, em casos ideias, a nosso ver, com o trabalho de equipe, juntado para um alvo comum linguistas e poetas iniciados na língua a ser traduzida. [...] o professor de língua [que] [...] não esteja bitolado por preconceitos acadêmicos, mas sim encontre na colaboração para a recriação de uma obra [...] (Campos 46-47)

Por isso, devo dizer que, ao revisitar a minha tradução dos cheiros do Chiclete, analisando-a e comparando-a com a tradução em espanhol, a sensação da angústia de não ter podido transmitir os cheiros em coreano adequadamente para o português foi substituída pelo arrependimento de não ter ousado mais, buscando sempre uma tradução mais exata, a qual se mostrou frustrante diante da "essência mesma da tradução de poesia o estatuto da impossibilidade" (Campos 121).

\section{Referências}

Campos, Haroldo de. A arte no horizonte do provável. São Paulo: Editora Perspectiva, 1977.

Campos, Haroldo de. Metaliguagem \& outras metas. São Paulo: Editora Perspectiva, 1992.

Correia, Donny. "Poeta sul-coreano Kim Ki-taek é traduzido pela primeira vez no Brasil”. O Estado de São Paulo, São Paulo, Aliás, 23 fev 2019. Disponível em: < https://alias.estadao.com.br/noticias/geral,poeta-sul-coreano-kim-ki-taeke-traduzido-pela-primeira-vez-no-brasil,70002732176> Acesso em: 
Kim, Ki-taek. El Chicle. Tradução de Sun-me Yoon. Toluca: Bonobos, 2013.

Kim, Ki-taek. Chiclete. Tradução de Yun Jung Im. Rio de Janeiro: 7Letras, 2018.

Kim, Ki-taek. "O sul-coreano Kim Ki-taek vem a São Paulo falar de 'Chiclete'ar". O Estado de São Paulo, São Paulo, Aliás, 07 fev 2019. Disponível em: < https:// alias.estadao.com.br/noticias/geral,o-sul-coreano-kim-ki-taek-vem-a-sao-paulofalar-de-chicletear,70002998776> Acesso em: 15/10/2019.

Kim, Si-seup. Contos da Tartaruga Dourada. Tradução de Yun Jung Im. São Paulo: Estação Liberdade, 2017.

Kwon, O-ryong. "Entrelinhas: Literatura Coreana”. TV Cultura, 01 ago 2010. Disponível em: tvcultura.com.br/videos/27642_entrelinhas-literatura-coreana. html. Acesso em: 15/09/2019.

Rabassa, Gregory. If this be treason: translation and its dyscontents, a memoir. Nova York: New Directions Books, 2005.

Shin, Dal-ja. "Entrelinhas: Literatura Coreana". TV Cultura, 01 ago 2010. Disponível em: <https://www.youtube.com/watch?v=zyxMSrNi0RY>. Acesso em: 15/09/2019

Taizé, Anthony of, Brother. "Translating Poetry". 3rd Korean Writers Forum in Gyeongju, 14 set 2017.Disponível em: < http://anthony.sogang.ac.kr/2017Trans latingKoreanPoetry.html > Acesso em: 15/09/2019.

Recebido em: 15/10/2019

Aceito em: 23/11/2019

Publicado em dezembro de 2019

Yun Jung Im. E-mail: estudoscoreanos@usp.br

ORCID: https://orcid.org/0000-0003-0272-4267 